\title{
23
}

\section{Conclusion - Elements of good design}

\section{Dean Ansell, Fiona Gibson and David Salt}

\begin{abstract}
Breaking News - Australia's national agricultural lobby, Farmers for Farmers, have just signed a historic accord with the conservation lobby, Conservationists at Large, pledging a redoubled effort to renew the natural values of our national farming estate. What makes the accord particularly noteworthy is that the federal government has acknowledged the importance of this new consensus and has pledged $\$ 3$ billion over five years to reverse the rising rate of extinctions, and declining quality of our land and water resources. The investment will be made primarily through a ramp up of the country's agrienvironment schemes. 'This is a once in a lifetime opportunity', says the prime minister.
\end{abstract}

Of course, this is a hypothetical news story, but you never know what lies around the political corner. The Decade of Landcare announced in 1989 was not anticipated by many in the years preceding it. While it was well received by all and sundry, it did not produce the level of enduring environmental outcomes that was expected (see Chapter 7 by David Salt).

Perhaps that is not surprising. Back then, our understanding of community-based natural resource management (NRM), robust environmental frameworks, market-based instruments, and 
environmental accounting was basic at best. A quarter of a century later, these fields have developed enormously, and we now have innumerable case studies to reflect on and learn from.

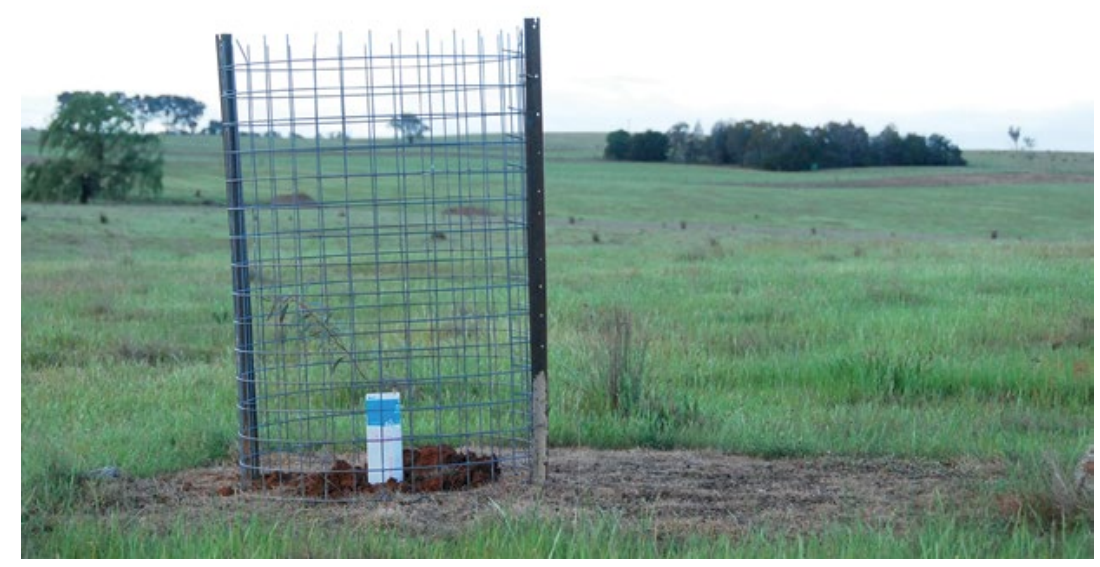

Figure 23.1: A native tree planted in a farm paddock in south east Australia.

Source: Photo by Dean Ansell.

So, when the next big opportunity to conserve biodiversity on farms comes around, will we be able to show that we have learnt from our experiences in agri-environmental policy? What are the key factors a policymaker needs to consider when designing and delivering an agri-environment scheme? Each chapter in this book provides valuable lessons and insights that policymakers should keep in mind when developing agri-environment schemes. We discuss here six central themes that have emerged from the discussions contained in the previous 22 chapters.

\section{Additionality}

Agri-environment schemes arguably have two main goals: (1) to shift certain agricultural practices and behaviours towards more environmentally sustainable alternatives; and (2) in doing so to protect or enhance environmental values. Consideration of both is critical. Faced with the decision of where to invest our scarce conservation 
funds, the decision maker should follow the mantra of any savvy investor and ask the question: 'where can I maximise my returns while minimising the risk?'

Additionality is a term used to define the size of the effect, or the amount of benefit, resulting from an action. In the context of agri-environment schemes, we can think about additionality from two different but equally important perspectives. The first concerns farmers' adoption of on-farm activities.

Consider a farmer who adopts an environmentally desirable agricultural practice and receives payment from an agri-environment scheme as a result. If the farmer had not received a financial incentive, would she have undertaken that specific practice anyway? If the answer is no, we would say that the benefits of the scheme are additional. If the answer is yes, however, we would say that the farmer has received a windfall - a payment for something she was going to do regardless of the scheme.

The extent of additionality achieved by agri-environment schemes varies widely. The USDA Agricultural Resources Management Survey for 2009-2011 showed that additionality in conservation payments ranges between 56 and 88 per cent, depending on the type of scheme (Claassen and Duquette 2014). In other words, for some schemes, close to half of the farmers receiving payments would have undertaken the particular action without the payment. An evaluation of several different agri-environment schemes in France showed that the complexity or scale of change required in farming practice influences additionality. The additionality of more complex measures such as a shift from conventional to organic farming was typically much higher than that of more simple measures (e.g. changing crop diversity) (Chabé-Ferret and Subervie 2013).

We can also think of additionality in terms of environmental outcomes, and ask whether the scheme has led to any change in conservation value or ecological condition. In Chapter 20, Phil Gibbons stresses the importance of focusing on those conservation actions that provide the highest additional benefits, specifically the greatest biodiversity gains relative to the status quo. In doing so, he challenges the traditional focus on investing in the conservation of high-quality habitats on farm land and instead advocates emphasis on 'smaller, more modified remnants that are more vulnerable to loss' and which provide the greatest biodiversity gains as they are starting from a lower ecological condition. 
A key challenge lies in identifying and measuring additionality, be it during the planning of an agri-environment scheme and selection of sites, or in retrospect during evaluation of a scheme's effectiveness. Both are important and contribute to improving the efficiency of conservation expenditure. However, as David Duncan and Paul Reich point out in Chapter 19, the consideration of additionality (through a comparison of results with and without the investment) is lacking in the evaluation of Australian agri-environment schemes. They also note that some decision makers hold the false perception that the use of counterfactuals in the evaluation of agri-environment schemes adds considerably to the cost of evaluation. They argue that simplified designs that ignore the counterfactual represent a waste of resources, as their results are unreliable. For an example of cost-effective monitoring and evaluation of agri-environment schemes, the reader is encouraged to review the work of David Lindenmayer and colleagues on the Environmental Stewardship Program (Lindenmayer et al. 2012).

\section{Longevity}

Program and project longevity is an important ingredient in designing effective agri-environment schemes. In Australia, agri-environmental schemes tend to be temporary and short-term - typically five years or less. Longevity refers to how long a particular agri-environment scheme (or program) needs to run to be successful. It refers to two different things: (1) whether a scheme is run for long enough to induce a change in landholder behaviour; and (2) whether it is long enough to achieve environmental objectives.

The first four chapters in Part 1 of this book (the agri-environment in the real world) all commented on the long-term nature of environmental action on private land.

'Achievement of these outcomes requires significant, long-term changes in land use and land management, which come at considerable financial and social cost to farmers', observes Geoff Park in Chapter 4.

In Chapter 2, Graham Fifield further supports this, noting that ongoing commitment to a site is important if the landholder is to achieve a good environmental return on the initial investment. 
Emma Burns and colleagues (Chapter 3) describe the Environmental Stewardship Program as a policy innovation that delivered this longterm support, providing payments over a 15 -year period, but note the challenge of operating such schemes over multiple political and accounting cycles. Indeed, the designed longevity of this program was possibly both its greatest strength and weakness (and a major reason it was discontinued).

But longevity is not just about the completion of on-ground works, numbers of hectares enrolled into a program, or even ecological benefit. It is just as much about changing the behaviour, attitudes, and values of landholders - a program needs to run long enough for this to occur. As David Pannell points out in his chapter on improving the performance of agri-environment schemes (Chapter 22), Australian programs provide only temporary support to farmers. Pannell notes that, where support is temporary, 'it is important to ensure that the actions being supported are attractive enough that farmers will continue to undertake them once funding ends. Otherwise the investment has no enduring benefit.'

When it comes to program longevity, enduring benefit is an important goal against which to judge policy proposals. And if the provision of long-term funding is not possible, then, as Pannell suggests in Chapter 22, a hard truth should be acknowledged about what should be funded: 'projects that would require significant funding in the long term to maintain the benefits generated by an initial project should not be supported.'

Long-term funding is important to creating enduring ecological and social outcomes, but it also contributes to the generation of human capital (skills and knowledge) and social capital (networks, trust and information sharing). Burns and colleagues concluded their review of the Environmental Stewardship Program in Chapter 3 with the observation that 'a valuable outcome that the Commonwealth secured through this program (in addition to the hectares being managed) was the relationships forged with the contracted land managers and developed with the CSIRO and ANU. These relationships should be nurtured to foster further learning and trust'. 
Longevity is also an important characteristic influencing the desirability of a scheme to land owners. When it comes to schemes based on tenders, Graeme Doole and Louise Blackmore found in Chapter 21 that 10-year contracts seemed the most desirable. They noted that shorter contracts (five years or less) often fail to achieve desired outcomes, whereas longer contracts (15 years or more) represent a longer commitment than farmers are willing to accept.

Further, farmers may require a higher price to enrol in programs that run for longer time frames and potentially impact on their agribusiness flexibility (Ruto and Garrod 2009).

In Chapter 13, Romy Greiner also commented on how the duration of a scheme influenced the willingness of land owners to participate. She noted that, for the land owners she surveyed, 'graziers were asking for a $\$ 0.40$ increase in annual per hectare payment ... for an additional year of contract duration'. (This might sound a paltry sum per hectare but keep in mind the properties she surveyed ranged in size from 2,500-10,000 $\mathrm{km}^{2}$.) This underlines a tension between land owners wanting to participate but not wanting to commit to anything for too long.

Given the short time frames of most programs, the role of environmental non-government organisations (eNGOs) as brokers is critical. As David Freudenberger states in Chapter 5:

The advantage of engaging a broker is the ability to build lasting relationships to help navigate the complexities and risks of entering and persisting in any market. Many eNGOs have persisted through decades of agri-environment schemes that often don't last for more than one election cycle. Continuity and organisational identity is a strength of many eNGOs.

\section{Policy mechanisms for changing behaviour}

The primary aim of an agri-environment scheme is to get landholders to adopt farming practices that deliver improved environmental outcomes. Over the years, a range of mechanisms have been used to try to achieve behavioural change. There have been payments, government regulation (to prevent damaging farming practices), tax advantages, extension(technology transfer, education, communication, 
demonstrations, support for community network), and development of improved land management options, such as through strategic $R \& D$, participatory R\&D with landholders, and provision of infrastructure to support a new management practice. Academic research and onground experience shows that the success of these mechanisms in changing behaviour is varied (Pannell et al. 2006). Several chapters in this book point to some of the reasons why.

First, the incentive for participating in a scheme is not always predominately financial. For example, the results of surveys of landholders presented in chapters 12,13 , and 21 reveal:

[Commercial] farmers rated environmental factors as most frequently influencing their adoption of native vegetation management practices (Chapter 12).

[F]armers in northern Australia have a high intrinsic stewardship motivation for safeguarding their cattle, land, and biodiversity assets, and that this is fundamentally linked to the pursuit of pastoralism as a chosen lifestyle (Chapter 13).

Landholders with an altruistic attitude and strong conservation focus, with a relatively low focus on monetary outcomes, are more likely to participate in future [conservation tender] programs (Chapter 21).

It is clear that at least some landholders adopt pro-conservation practices voluntarily, without requiring payments. For example, Saan Ecker in Chapter 12 described a survey of landholder motivations to participate in the Environmental Stewardship Program. She noted: 'Most respondents "strongly agreed" that conservation and enhancement of native vegetation contributed to improved property or landscape health, aesthetics, soil stabilisation, and controlling rising water tables.'

Another example is Chapter 14, in which Maksym Polyakov and David Pannell estimate the extent to which private benefits from native vegetation on farms are built into the price of land, and how those price premiums vary in different circumstances. One potential problem occurring when there are private benefits from conservation is that these benefits are not additional (as discussed earlier). 
Another is the problem of 'crowding out', where government funding for a practice reduces the level of unfunded voluntary adoption of that practice by people who are not supported by the program. This can occur if landholders feel that it is unfair for them to receive no recognition for their voluntary efforts while other landholders are receiving payments for the same actions. Graeme Doole and Louise Blackmore in Chapter 21 note that 'tender programs must employ options to counteract crowding out if they are to achieve additional environmental outcomes'. It's not obvious what these other options may be - aside from not to provide incentive payments at all and is therefore an issue worthy of further research.

We have also seen that flexibility in delivery mechanisms is important. For example, the features of a land management contract may encourage or inhibit landholder participation if certain conditions aren't available. As Greiner states in Chapter 13: 'in general, farmers prefer higher payments, shorter contracts, more flexibility, less accountability and less paperwork.' This is a point supported by Doole and Blackmore in Chapter 21. The importance of each of these features is likely to vary depending on the location, farming system, and characteristics of the landholder. We don't suggest that policymakers pander to these desires - there are public benefits from opposite contract features - rather that they weigh up the public benefits and private costs in delivery mechanisms.

The message here is that agri-environment scheme designers should carefully consider the range of policy mechanisms they use, as some will be more suitable for some groups of farmers than others. Several evaluations of the effectiveness of schemes, both in Australia (e.g. Michael et al. 2014) and around the world (e.g. Gabriel et al. 2010), have found that a one-size-fits-all approach often fails to deliver the best biodiversity outcomes.

\section{Prioritisation}

We need to prioritise because there is never enough money available to fund all the available projects. To maximise the environmental benefits delivered by the budget of a program, governments should seek to deliver the best possible value for money. This is done by comparing 
the benefits and costs of proposed projects and funding those that provide the best return on investment - that is, the highest ratio of benefits to costs (Joseph et al. 2009).

In his chapter on improving the performance of agri-environment programs (Chapter 22), David Pannell provides a checklist of the key aspects of (cost-effective) prioritisation including a focus on projects (actions); ranking according to value for money; using counterfactuals to calculate benefits (as the difference in outcomes with versus without the investment); incorporating all the benefits and risks; and using a sound metric to rank investments. These elements were highlighted separately in several chapters.

Central to the prioritisation process is the explicit consideration of the costs of each project. Failing to acknowledge cost, or failing to appropriately compare costs between projects, has been a major weakness of project prioritisation in the past (Pannell 2013) and is poorly done across environmental evaluation in general (Wortley et al. 2013; Armsworth 2014). This is one of the key reasons that Pannell recommends that prioritisation should be applied to projects or actions, not to different regions, problems, and issues. Only by defining projects is it possible to meaningfully estimate investment costs.

Projects should be ranked according to value for money - a measure of their benefit divided by their cost. In Chapter 15, Dean Ansell points out that the application of this simple principle could result in significant improvements in efficiency in conservation expenditure. He also notes that there is a variety of simple economic tools available to perform such evaluations that remain relatively under-used.

Decision makers should make sure all the benefits and risks are being incorporated. If the level of adoption or likelihood of success is not factored in when projects are being ranked, inferior projects may be selected. Saan Ecker (Chapter 12) and Romy Greiner (Chapter 13) both discuss the importance of understanding the willingness of land managers to participate in agri-environment schemes as being central to the success of the projects included in the schemes.

As Fiona Gibson and David Pannell explain in Chapter 17, the way the metric used to rank projects is calculated and the choice of variables included are important. Errors here can lead to significant losses of environmental benefits. Interestingly, they also show that investing in 
the collection of accurate information for ranking projects may not be as critical as is often assumed. In many cases, improving the quality of the metric used to rank projects makes a larger impact on the overall level of benefits generated by a program.

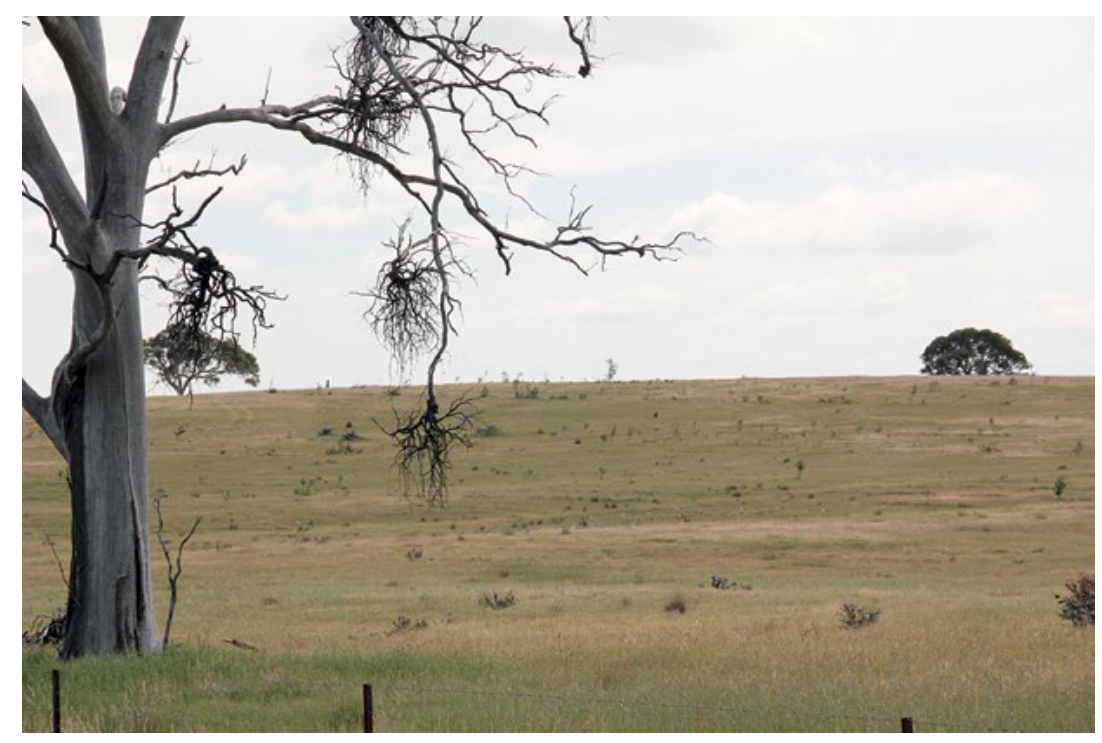

Figure 23.2: A failed effort at native revegetation on a farm in NSW.

Source: Photo by David Salt.

\section{Managing risk and uncertainty}

As with many types of investment, agri-environment schemes carry significant risks. Chief among these is the risk of failure - primarily the failure to achieve the intended conservation outcomes, which in essence translates to the failure of the scheme. While there are many examples of successful agri-environment schemes, there are many that have failed to achieve their objectives or even led to negative consequences. For example, an evaluation of agri-environment schemes in Victoria found little evidence for benefits to the conservation of reptiles and amphibians (Michael et al. 2014), while a large scheme in Ireland led to an increase in agricultural pests, at the same time failing to achieve its goal of increasing the abundance of the threatened Irish hare (Reid et al. 2007). In Italy, declines in the population of the corn 
crake, a threatened grassland bird found in farmland, coincided with the introduction of government subsidies for grassland conservation management (Brambilla and Pedrini 2013).

Outcomes such as these may be partly or fully attributed to poor planning and implementation, but are often the result of unexpected ecological response to management. The process of ecological restoration, a primary aim of many agri-environment schemes, is complex and remains poorly understood, particularly in agricultural landscapes where the legacies of past land use and current management and climatic factors create much uncertainty in the response of biodiversity to conservation. This uncertainty not only has the potential to impact on the environmental values delivered from agri-environment schemes, but, as Sayed Iftekhar and colleagues remind us in Chapter 10, also impacts on the adoption of scheme practices. Repeated failures run the risk of alienating farmers and undermining their participation in future schemes.

This underscores the importance of a number of key factors in the design and implementation of agri-environment schemes. In particular, it highlights that identifying specific objectives for conservation is critical in defining and demonstrating success, yet the omission of such objectives is a perennial issue (Hobbs 2007). As Geoff Park outlines in Chapter 4, the use of SMART (Specific, Measurable, Achievable, Relevant, and Time-Bound) targets is crucial in the design of the scheme. Not only do SMART targets play a key role in establishing project budgets and time frames, but they also provide a centrepiece for negotiations with farmers around the aims, feasibility, and risks of proposed interventions.

Several chapters in this book contain ideas and strategies for managing risk in agri-environment schemes. The benefits of starting small as a risk mitigation strategy is highlighted by several authors. We learnt in Chapter 2 that Greening Australia's successful Whole of Paddock Rehabilitation (WOPR) scheme started with a single pilot site, which served not only as a way to assess the feasibility of the approach, but also as a demonstration to farmers interested in the program. As the saying goes, the proof is in the pudding. The Environmental Stewardship Program scheme also started small, focusing on a single target ecosystem and using the outcomes of that initial stage to broaden the coverage of the scheme as it evolved (see Chapter 3). 
As David Freudenberger points out in Chapter 5, the level of acceptable risk differs between types of organisations. Non-government organisations, being largely free of the political constraints of government agencies, typically display a higher willingness to fail, and can therefore play a key role in innovation and trialling new approaches.

It is worth remembering, however, that many risks associated with agri-environment schemes, such as the uncertainty in ecological response, cannot be entirely removed. The efforts of the decision maker will be better spent factoring risk into the planning and prioritisation of agri-environment schemes, with various tools available to assist (see the simple metric provided by Fiona Gibson and David Pannell in Chapter 17, which includes the probability of success). The use of an adaptive management framework to identify, respond to, and learn from this uncertainty and unpredictability is strongly advocated by researchers (Lindenmayer et al 2008; Sayer et al. 2013). It should be noted that such an approach brings additional challenges (e.g. funding, expertise), albeit surmountable, for the policymaker.

Above all, understanding, acknowledging, and communicating these risks, particularly the risk of failure, was identified by many of our contributing authors as a critical factor in agri-environmental policy.

\section{Capacity}

In Chapter 22, David Pannell provides a list of 22 elements of good agri-environment scheme design. There was a 23rd element put forward by Pannell: 'success requires recognition that there is a body of expertise that needs to be mastered ... Agencies with responsibility for agri-environment programs should foster the development of this expertise amongst their staff.' Which leads us to our final theme capacity. Capacity is not just about the skills and knowledge contained in the organisations running these schemes; it also relates to the human and social capital found in the regions where agri-environment schemes are being implemented (Curtis and Lefroy 2010).

This book makes it clear that designing, implementing, and managing robust and effective agri-environmental programs requires a range of knowledge and technical skills. For agri-environment schemes 
to be effective, these skills and knowledge need to be available to policymakers, NRM managers, and the landholders participating in the schemes.

There are a number of ways to develop expertise amongst agency staff. The three approaches recommended by Cook et al. (2013) are: scientists embedded within agencies (internships), formal links between researchers and decision makers, and staff training. Formal links between researchers and scientists are facilitated through various government programs, such as cooperative research centres, Australian Research Council Linkage Projects and programs such as the National Environmental Research Program run by the Australian Department of the Environment. However, as pointed out by Emma Burns and colleagues in Chapter 3, the issue of dealing with scientific knowledge and its application in agri-environment policy within a government department is challenging and will require cultural reform for a more effective integration in future. Attwood and Burns (2012) discuss the disjunct between the spheres of science and NRM policy, suggesting it is systematic in nature. They recommend that scientists need to spend more time understanding the policymakers' bureaucratic and hierarchical system, while the public service structure needs to better reward scientific literacy.

Returning to the issue of landholder capacity, Graham Fifield and David Freudenberger both pointed out in their chapters (chapters 2 and 5 respectively) that landholders and agencies working in the agrienvironment need somewhere to turn when things go wrong. Often they seek advice from trusted sources - other landholders, locals, and environmental NGOs they have worked with over time. In recent decades, there have been cutbacks to the level of extension services offered by government (Pannell et al. 2006), and staffing levels of many NRM organisations (Curtis et al. 2014), all of which erodes the capacity of agencies and communities to participate in agri-environment schemes.

In his brief history of agri-environment programs (Chapter 7), David Salt noted that earlier investments in agri-environment programs focused more on building social capital (networks and community groups) and human capital (knowledge and awareness) than targeting specific environmental outcomes. Over time, we have improved our knowledge of what is required to develop programs that will generate 
these outcomes. It is clear that enhancement of landholder capacity remains an important element of programs, although it is not the only element. There are likely to be benefits from targeting efforts to build capacity to situations where it can make the greatest difference to environmental outcomes.

\section{Box 23.1: The question of value.}

The question of value arises throughout this book. It also underpinned much of the discussion at the workshop that gave rise to the book. Whose values are we talking about? Which values do we mean? How do we ensure value for money? Will there ever be enough political pressure for society to adequately protect the multiple values provided by our agricultural landscapes?

During workshop discussions, Rob Fraser, an economist based in the United Kingdom, pointed out that the broader UK society placed a high value on the country's agricultural landscapes. They wanted this landscape to be available for the public to access for recreation, but they also wanted it to be there because it was part of their shared cultural history - even if they never visit it. This led him to raise the issue of different types of value: use values and non-use values.

The use values of an agricultural landscape are the benefits it generates through people making direct use of it, such as for agricultural production (e.g. cropping and livestock activities), or recreation.

Non-use values arise when an agricultural landscape generates benefits even without people making direct use of it. Examples include existence value (the benefit of knowing that the landscape still exists in good environmental condition) or option value (the benefit of retaining the landscape in a condition that does not rule out various options for its future use).

In the UK, much of the agricultural landscape provides a combination of these use and non-use values, with the social-use value of recreation particularly recognised by policymakers. This feature is set to continue into the future, with recent agri-environmental policy changes identifying the need to target areas of land for the provision of recreation values near major urban sites (European Commission 2013).

In Australia, Rob suggested the balance of social values in relation to the agricultural landscape is more towards the non-use value of nature conservation, and less towards the use value of recreation of the UK. It seems likely that nonuse values would be considered by many people to be less significant than use values, reducing the prospect of major increases in public funding in the Australian context. 


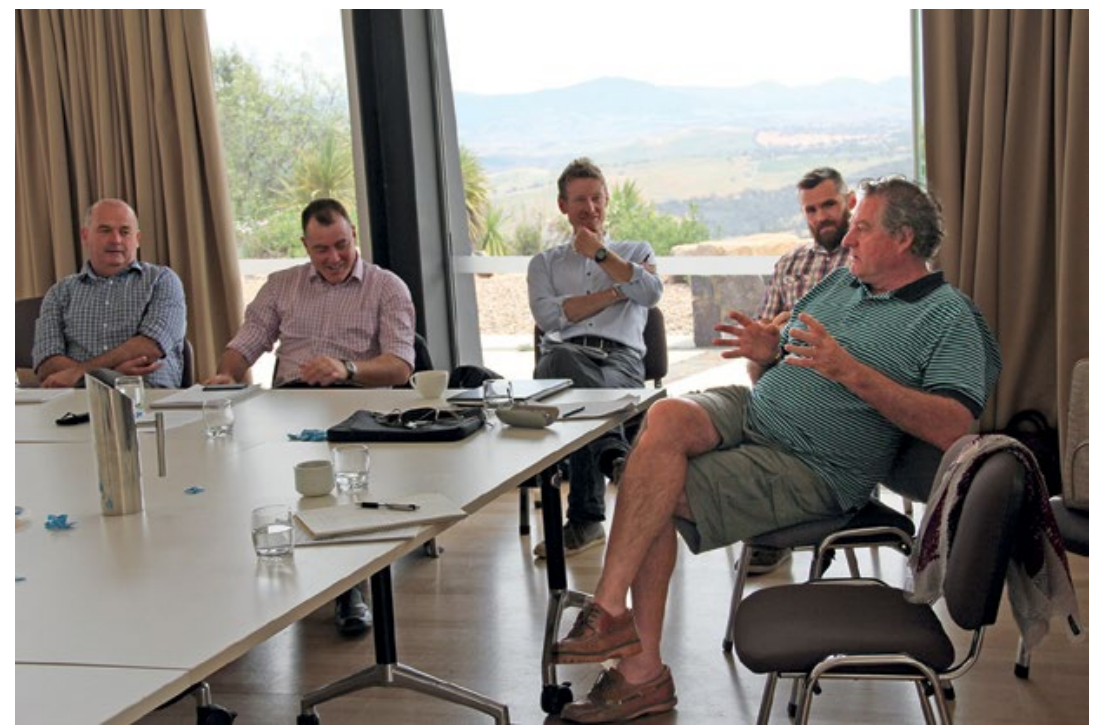

Figure 23.3: Rob Fraser (on the right) at the agri-environment scheme workshop discussing how the UK society values the country's agricultural landscapes. Australia's agricultural landscapes can be glimpsed in the windows in the background. Source: Photo by David Salt.

\section{Making 'the next big thing' a success story?}

Despite the many challenges and criticisms of agri-environment schemes, the fact remains that they represent one of the strongest tools available in the quest to conserve biodiversity in farming landscapes. In our opening chapter, we discussed two contrasting schemes: one focused on restoration (WOPR, see Chapter 2), and the other on conservation (the Environmental Stewardship Program, see Chapter 3), and asked a set of questions about which was better and where the community is most likely to get value for money? The answers to these questions, of course, are 'it depends'.

We would now qualify this context-dependent answer by stating that we believe that the key criteria for successful agri-environmental policy making revolve around our six central themes of additionality, longevity, the application of appropriate policy mechanisms, robust prioritisation, effective risk management, and sufficient levels of capacity. 
There are no simple black-and-white answers in addressing these themes, but it is important that the policy designer, implementer, and manager can, at the very least, frame more specific questions against each of them. Our aim in this book has been to help with that framing (and we would emphasise the more detailed list of questions posed by David Pannell in Chapter 22 - see Box 22.1).

If the public mood or political pendulum were to suddenly give rise to a large amount of money being put up for an agri-environment program across Australia, would we as a nation be ready to make the most of it? It is our opinion that we have both the experience and expertise on hand to improve substantially upon past performance.

\section{References}

Armsworth, P.R. (2014) 'Inclusion of costs in conservation planning depends on limited datasets and hopeful assumptions', Annals of the New York Academy of Sciences 1322(1): 61-76. DOI:10.1111/ nyas. 12455.

Attwood, S.J. and E. Burns (2012) ‘Managing biodiversity in agricultural landscapes: Perspectives from a research-policy interface', Land use intensification: Effects on agriculture, biodiversity and ecological processes (eds D.B. Lindenmayer, S. Cunningham and A. Young), CSIRO Publishing, Melbourne, pp. 17-26.

Brambilla, M. and P. Pedrini (2013) 'The introduction of subsidies for grassland conservation in the Italian Alps coincided with population decline in a threatened grassland species, the Corncrake Crex crex', Bird Study 60(3): 404-8. DOI:10.1080/00063657.2013.8 11464.

Chabé-Ferret, S. and J. Subervie (2013) 'How much green for the buck?: Estimating additional and windfall effects of French agroenvironmental schemes by DID-matching', Journal of Environmental Economics and Management 65(1): 12-27. DOI:10.1016/j.jeem.2012. 09.003 .

Claassen, R. and E. Duquette (2014) Additionality in agricultural conservation programs, USDA Economic Research Service Report No. 170. Available at: www.ers.usda.gov/media/1534156/err170.pdf. 
Cook, C.N., M.B. Mascia, M.W. Schwartz, H.P. Possingham and R.A. Fuller (2013) Achieving conservation science that bridges the knowledge-action boundary', Conservation Biology 27(4): 669-78.

Curtis, A.L. and E.C. Lefroy (2010) 'Beyond threat- and assetbased approaches to natural resource management in Australia', Australian Journal of Environmental Management 17: 134-41.

Curtis, A., H. Ross, G.R. Marshall, C. Baldwin, et al. (2014) 'The great experiment with devolved NRM governance: Lessons from community engagement in Australia and New Zealand since the 1980s', Australasian Journal of Environmental Management 21(2): 175-99.

European Commission (2013) Overview of CAP Reform 2014-2020, Agricultural Perspectives Policy Brief No. 5. Available at: ec.europa. eu/agriculture/policy-perspectives/policy-briefs/05_en.pdf.

Fischer, J., J. Stott, A. Zerger, et al. (2009) Reversing a tree regeneration crisis in an endangered ecoregion, PNAS. Available at: www.pnas. org/content/106/25/10386.full.pdf.

Gabriel, D., S.M. Sait, J.A. Hodgson, et al. (2010) 'Scale matters: The impact of organic farming on biodiversity at different spatial scales', Ecology Letters 13: 858-69. DOI:10.1111/j.1461-0248.2010.01481.x.

Hobbs, R.J. (2007) 'Setting effective and realistic restoration goals: Key directions for research', Restoration Ecology 15: 354-7. DOI:10.1111/j.1526-100X.2007.00225.x.

Joseph, L.N., R.F. Maloney and H.P. Possingham (2009) 'Optimal allocation of resources among threatened species: A project prioritization protocol', Conservation Biology 23: 328-38.

Lindenmayer, D., R.J. Hobbs, R. Montague-Drake, et al. (2008) A checklist for ecological management of landscapes for conservation', Ecology Letters 11(1): 78-91. DOI:10.1111/j.14610248.2007.01114.x.

Lindenmayer, D.B., C. Zammit, S.J. Attwood, et al. (2012) 'A novel and cost-effective monitoring approach for outcomes in an Australian biodiversity conservation incentive program', PloS ONE 7(12): e50872. DOI:10.1371/journal.pone.0050872. 
Michael, D.R., J.T. Wood, M. Crane, et al. (2014) 'How effective are agri-environment schemes for protecting and improving herpetofaunal diversity in Australian endangered woodland ecosystems?', Journal of Applied Ecology 51(2): 494-504. DOI:10.1111/1365-2664.12215.

Pannell, D.J. (2008) 'Public benefits, private benefits, and policy mechanism choice for land-use change for environmental benefits', Land Economics 84(2): 225-40.

Pannell, D.J. (2013) Ranking environmental projects, Working Paper 1312, School of Agricultural and Resource Economics, University of Western Australia. Available at: ageconsearch.umn. edu/handle/156482.

Pannell, D.J., G.R. Marshall, N. Barr, et al. (2006) ‘Understanding and promoting adoption of conservation practices by rural landholders', Australian Journal of Experimental Agriculture 46: 1407-24.

Polyakov, M., D.J. Pannell, R. Pandit, S. Tapsuwan and G. Park (2015) 'Capitalized amenity value of native vegetation in a multifunctional rural landscape', American Journal of Agricultural Economics 97(1): 299-314.

Reid, N., R.A. McDonald and W.I. Montgomery (2007) 'Mammals and agri-environment schemes: Hare haven or pest paradise?', Journal of Applied Ecology 44: 1200-8. DOI:10.1111/j.1365-2664. 2007.01336.x.

Ruto, E. and G. Garrod (2009) 'Investigating farmers' preferences for the design of agri-environment schemes: A choice experiment approach', Journal of Environmental Planning and Management 52(5): 631-47. DOI:10.1080/09640560902958172.

Sayer, J., T. Sunderland, J. Ghazoul, et al. (2013) 'Ten principles for a landscape approach to reconciling agriculture, conservation, and other competing land uses', Proceedings of the National Academy of Sciences of the United States of America 110(21): 8349-56. DOI:10.1073/pnas.1210595110.

Wortley, L., J.M. Hero and M. Howes (2013) 'Evaluating ecological restoration success: A review of the literature', Restoration Ecology 21: 537-43. DOI:10.1111/rec.12028. 
This text is taken from Learning from agri-environment schemes in Australia: Investing in biodiversity and other ecosystem services on farms, edited by Dean Ansell, Fiona Gibson and David Salt, published 2016 by ANU Press, The Australian National University, Canberra, Australia. 